\title{
Quantitative cerebral blood flow using xenon-enhanced CT after decompressive craniectomy in traumatic brain injury
}

\author{
Aditya Vedantam, MD, Claudia S. Robertson, MD, and Shankar P. Gopinath, MD \\ Department of Neurosurgery, Baylor College of Medicine, Houston, Texas
}

OBJECTIVE Few studies have reported on changes in quantitative cerebral blood flow (CBF) after decompressive craniectomy and the impact of these measures on clinical outcome. The aim of the present study was to evaluate global and regional CBF patterns in relation to cerebral hemodynamic parameters in patients after decompressive craniectomy for traumatic brain injury (TBI).

METHODS The authors studied clinical and imaging data of patients who underwent xenon-enhanced CT (XeCT) CBF studies after decompressive craniectomy for evacuation of a mass lesion and/or to relieve intractable intracranial hypertension. Cerebral hemodynamic parameters prior to decompressive craniectomy and at the time of the XeCT CBF study were recorded. Global and regional CBF after decompressive craniectomy was measured using XeCT. Regional cortical $\mathrm{CBF}$ was measured under the craniectomy defect as well as for each cerebral hemisphere. Associations between CBF, cerebral hemodynamics, and early clinical outcome were assessed.

RESULTS Twenty-seven patients were included in this study. The majority of patients $(88.9 \%)$ had an initial Glasgow Coma Scale score $\leq 8$. The median time between injury and decompressive surgery was 9 hours. Primary decompressive surgery (within 24 hours) was performed in the majority of patients $(n=18,66.7 \%)$. Six patients had died by the time of discharge. XeCT CBF studies were performed a median of 51 hours after decompressive surgery. The mean global $\mathrm{CBF}$ after decompressive craniectomy was $49.9 \pm 21.3 \mathrm{ml} / 100 \mathrm{~g} / \mathrm{min}$. The mean cortical CBF under the craniectomy defect was $46.0 \pm 21.7 \mathrm{ml} / 100 \mathrm{~g} / \mathrm{min}$. Patients who were dead at discharge had significantly lower postcraniectomy CBF under the craniectomy defect $(30.1 \pm 22.9$ vs $50.6 \pm 19.6 \mathrm{ml} / 100 \mathrm{~g} / \mathrm{min} ; \mathrm{p}=0.039)$. These patients also had lower global $\mathrm{CBF}(36.7 \pm 23.4$ vs $53.7 \pm 19.7 \mathrm{ml} / 100 \mathrm{~g} / \mathrm{min} ; p=0.09)$, as well as lower CBF for the ipsilateral ( $33.3 \pm 27.2$ vs 51.8 $\pm 19.7 \mathrm{ml} / 100 \mathrm{~g} / \mathrm{min} ; p=0.07)$ and contralateral $(36.7 \pm 19.2 \mathrm{vs} 55.2 \pm 21.9 \mathrm{ml} / 100 \mathrm{~g} / \mathrm{min} ; p=0.08)$ hemispheres, but these differences were not statistically significant. The patients who died also had significantly lower cerebral perfusion pressure ( $52 \pm 17.4$ vs $75.3 \pm 10.9 \mathrm{~mm} \mathrm{Hg} ; p=0.001)$.

CONCLUSIONS In the presence of global hypoperfusion, regional cerebral hypoperfusion under the craniectomy defect is associated with early mortality in patients with TBI. Further study is needed to determine the value of incorporating $\mathrm{CBF}$ studies into clinical decision making for severe traumatic brain injury.

https://thejns.org/doi/abs/10.3171/2017.4.JNS163036

KEY WORDS traumatic brain injury; cerebral blood flow; xenon-enhanced CT; decompressive craniectomy

$\mathrm{D}$ ECOMPRESSIVE craniectomy has been shown to reduce intracranial pressure (ICP) in patients with traumatic brain injury (TBI), although this does not consistently result in favorable clinical outcomes. ${ }^{2}$ Unfavorable clinical outcomes after decompressive craniectomy for TBI have been thought to be due to cerebral edema, altered cerebral blood flow (CBF), and metabolic dysfunction. ${ }^{4}$ At this time, more data are needed on chang- es in cerebral hemodynamics after decompressive craniectomy to better assist in prognostication.

There are limited data on changes in microvascular cerebral perfusion after decompressive craniectomy. ${ }^{12}$ Changes in the patterns of global and regional CBF are not well defined in patients undergoing decompressive surgery. Although early quantitative microvascular perfusion to the cortex has been shown to correlate with clinical

ABBREVIATIONS CBF = cerebral blood flow; CPP = cerebral perfusion pressure; GCS = Glasgow Coma Scale; GOS = Glasgow Outcome Scale; ICP = intracranial pressure; ICU = intensive care unit; $\mathrm{PbtO}_{2}=$ brain tissue oxygenation; $\mathrm{SjVO}_{2}=$ jugular venous oxygen saturation; $\mathrm{TBI}=$ traumatic brain injury; $\mathrm{XeCT}=$ xenon-enhanced $\mathrm{CT}$. SUBMITTED December 2, 2016. ACCEPTED April 4, 2017.

INCLUDE WHEN CITING Published online October 13, 2017; DOI: 10.3171/2017.4.JNS163036. 
outcomes after TBI, ${ }^{11}$ clinical correlates of these metrics after decompressive craniectomy have not been explored.

The aim of the present study was to evaluate global and regional CBF patterns in relation to cerebral hemodynamic parameters in patients after decompressive craniectomy for TBI.

\section{Methods}

We studied prospectively collected clinical and imaging data for patients with TBI who underwent quantitative CBF measurements using stable xenon-enhanced CT (XeCT) imaging. XeCT CBF was performed per an investigational study protocol designed to study regional CBF after TBI. For the present study, we selected only those patients who underwent XeCT CBF studies after a decompressive craniectomy for evacuation of a mass lesion and/ or to relieve intractable intracranial hypertension. All patients were admitted to a neurosurgical intensive care unit (ICU) and managed according to the guidelines described by the Brain Trauma Foundation. Patients with mass lesions requiring emergency decompressive surgery (primary decompressive surgery) were admitted to the ICU postoperatively. Secondary decompressive surgery was performed after admission to the ICU for patients with intractable intracranial hypertension that was resistant to maximum medical therapy. Maximum medical therapy for intracranial hypertension included the use of an external ventricular drain for CSF drainage, sedation, paralytics, mannitol, and initiation of pentobarbital coma.

Demographic, clinical, and follow-up data for the patients in this study are maintained in a research database at our institution. Prehospital and admission clinical and imaging data including Glasgow Coma Scale (GCS) scores, pupillary examination, mechanism of injury, Abbreviated Injury Scale scores, ${ }^{7}$ and initial Marshall CT classification $^{13}$ were reviewed. If available, average cerebral hemodynamic parameters (ICP, cerebral perfusion pressure [CPP], jugular venous oxygen saturation $\left[\mathrm{SjvO}_{2}\right]$, and brain tissue oxygenation $\left[\mathrm{PbtO}_{2}\right]$ prior to decompressive craniectomy) were recorded. All values were monitored continuously and recorded once an hour. Similar parameters were recorded at the time of the XeCT CBF study. Outcomes were measured at discharge and at 6-month follow-up visits using the Glasgow Outcome Scale (GOS).

$\mathrm{XeCT}$ CBF studies were performed as previously described ${ }^{6,17}$ after patients were hemodynamically stable in the ICU. Four to 6 axial slices, each $5 \mathrm{~mm}$ thick and $20 \mathrm{~mm}$ apart, from posterior fossa to vertex were obtained (Figs. 1 and 2). Continuous monitoring of end-expiratory $\mathrm{CO}_{2}$, xenon as well as arterial blood pressure, and ICP (when available) was performed. The earliest XeCT CBF study performed after decompressive craniectomy was selected for analysis. Images were analyzed using proprietary software (Diversified Diagnostic Products, Inc.). Global CBF was measured using a preset template that demarcated the cortical mantle. Regional CBF was measured using manual regions of interest in the cortical mantle under the craniectomy for the ipsilateral decompressed cerebral hemisphere and the contralateral hemisphere.

For patients who underwent bifrontal decompressive
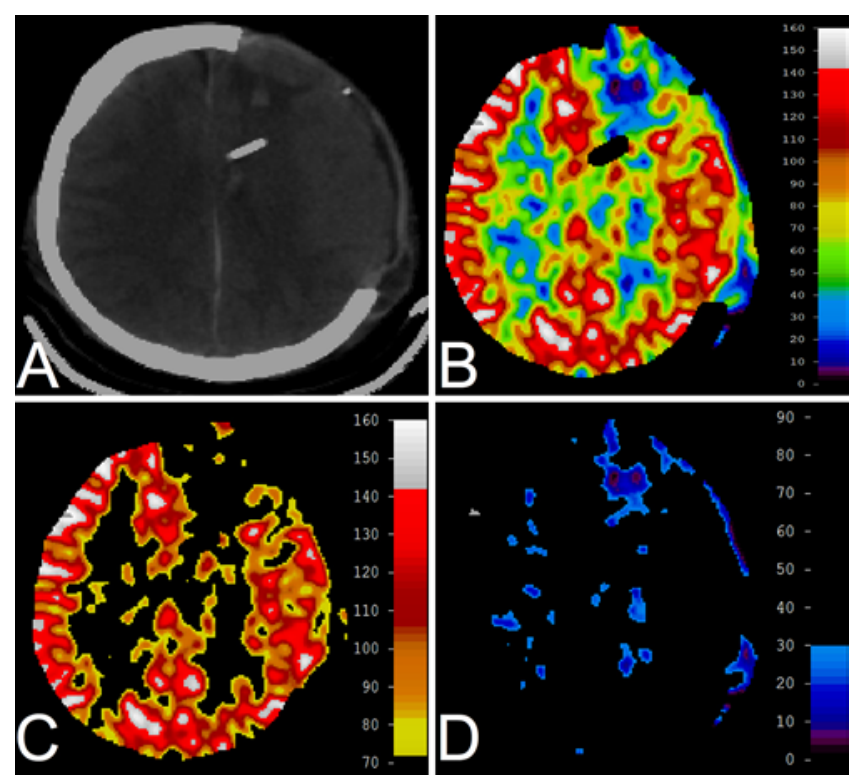

FIG. 1. Postoperative noncontrast head CT (A) and corresponding XeCT $\mathrm{CBF}$ image (B) showing hyperemia in the ipsilateral and contralateral cerebral cortex after left decompressive craniectomy. High-pass filter (C) (> $70 \mathrm{ml} / 100 \mathrm{~g} / \mathrm{min}$ ) and low-pass filter (D) $(<30 \mathrm{ml} / 100 \mathrm{~g} / \mathrm{min})$ processed images of CBF show large areas of hyperemia throughout the cortex and few areas of ischemia. Figure is available in color online only.

craniectomy, the side of the larger craniectomy defect was categorized as the ipsilateral side. In 2 patients, manual regions of interest could not be drawn, and data from the preset template were used to calculate regional CBF. For 10 patients, XeCT CBF data were available prior to decompressive craniectomy, and regional and global CBF data were measured using the preset template. $\mathrm{CBF}$ values
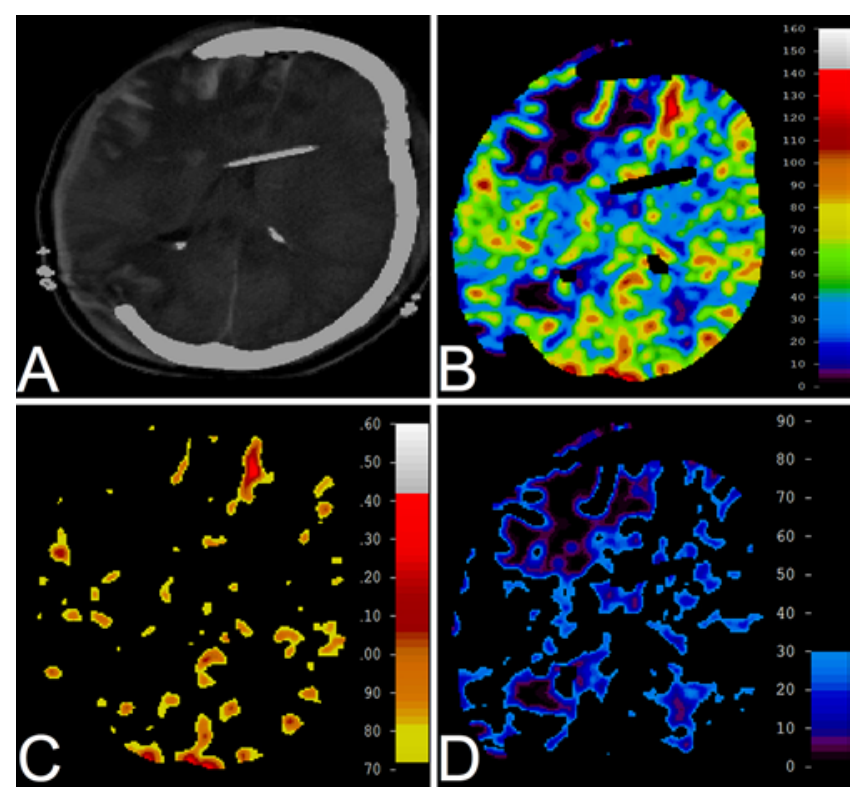

FIG. 2. Noncontrast CT (A) and XeCT CBF (B) images obtained in a patient with $\mathrm{TBI}$ after right decompressive hemicraniectomy showing minimal hyperemia (C) $>70 \mathrm{ml} / 100 \mathrm{~g} / \mathrm{min})$ and larger areas of ischemia (D) $(<30 \mathrm{ml} / 100 \mathrm{~g} / \mathrm{min})$. Figure is available in color online only. 
were categorized as core $(0-8 \mathrm{ml} / 100 \mathrm{~g} / \mathrm{min})$, penumbra (9-30 ml/100 g/min), normal (31-70 ml/100 g/min), and hyperemia (> $70 \mathrm{ml} / 100 \mathrm{~g} / \mathrm{min}){ }^{6,11}$

Statistical analysis was performed using IBM SPSS version 20.0. Descriptive statistics were used for demographic and clinical data. Normality of data was determined using the Shapiro-Wilk test. Parametric comparisons for patient survival were performed using the Student t-test. Nonparametric comparisons between pre- and postcraniectomy XeCT data were performed using the Kruskal-Wallis test. Statistical significance was set at $\mathrm{p}<0.05$.

\section{Results}

Twenty-seven patients were included in this study. Eighteen patients underwent CBF studies in the ICU using a portable CT scanner, and 9 patients required transport to the main $\mathrm{CT}$ scanner for $\mathrm{CBF}$ imaging. The majority of patients $(\mathrm{n}=18)$ had more than 1 XeCT CBF study, and the median number of scans was 2 per patient. Demographic, clinical, and imaging data at admission are shown in Table 1. Three patients (11.1\%) had prehospital hypoxia, and 1 patient $(3.7 \%$ ) had prehospital hypotension. The majority of patients $(88.9 \%)$ had an initial GCS score $\leq 8$. The median time between injury and decompressive surgery was 9 hours (range 1-162 hours). Primary decompressive surgery (within 24 hours) was performed in the majority of patients $(n=18,66.7 \%)$.

XeCT CBF studies were performed a median of 51 hours (range 4-384 hours) after decompressive surgery. The mean CPP prior to XeCT CBF $(n=22)$ was significantly lower compared with CPP at the time of the CBF study $(60.8 \pm 15.5$ vs $69.3 \pm 16.2 \mathrm{~mm} \mathrm{Hg} ; \mathrm{p}=0.03)$. The mean ICP prior to XeCT CBF $(n=22)$ was higher than the ICP at the time of the CBF study $(27.1 \pm 13.3$ vs $20.4 \pm$ $12.7 \mathrm{~mm} \mathrm{Hg} ; \mathrm{p}=0.06)$. Comparisons for $\mathrm{PbtO}_{2}$ and $\mathrm{SjvO}_{2}$ values showed no significant difference $(\mathrm{p}=0.47$ and $\mathrm{p}=$ 0.28 , respectively; $\mathrm{n}=9$ ) at the 2 time points. The $\mathrm{PbtO}_{2}$ probe was adjacent to a cortical contusion in 3 patients who died and 3 patients who survived. In the rest of the patients, the probe was in normal-appearing cortex.

The mean global CBF after decompressive craniectomy was $49.9 \pm 21.3 \mathrm{ml} / 100 \mathrm{~g} / \mathrm{min}$. The mean cortical $\mathrm{CBF}$ under the craniectomy defect was $46.0 \pm 21.7 \mathrm{ml} / 100$ $\mathrm{g} / \mathrm{min}$. There was no significant difference in the mean hemispheric CBF ipsilateral to the craniectomy versus contralateral to the craniectomy defect $(47.7 \pm 22.4$ vs 51.1 $\pm 22.4 \mathrm{ml} / 100 \mathrm{~g} / \mathrm{min} ; \mathrm{p}=0.17$ ). Categorized $\mathrm{CBF}$ values after decompressive surgery are shown in Table 2.

Comparisons of pre- and postcraniectomy global CBF showed a higher CBF after surgery in 10 patients; however, the difference was not statistically significant ( $44.8 \pm$ 11.7 vs $49.7 \pm 13.4 \mathrm{ml} / 100 \mathrm{~g} / \mathrm{min} ; \mathrm{p}=0.16$ ) (Fig. 3). Prior to craniectomy, 9 patients had normal CBF $(31-70 \mathrm{ml} / 100 \mathrm{~g} /$ $\mathrm{min}$ ), and 1 patient had low/penumbra CBF (9-30 ml/100 $\mathrm{g} / \mathrm{min})$. After decompressive surgery, low $\mathrm{CBF}$ persisted in 1 patient, 8 patients had normal $\mathrm{CBF}$, and 1 patient had hyperemia (> $70 \mathrm{ml} / 100 \mathrm{~g} / \mathrm{min})$.

At discharge from the hospital, 6 patients had died, 8 patients were in a persistent vegetative state, and 12 patients had severe disability. No GOS score was recorded
TABLE 1. Baseline demographic and clinical data for 27 patients who underwent XeCT CBF scanning after decompressive craniectomy for TBI

\begin{tabular}{|c|c|c|}
\hline Variable & No. & $\%$ \\
\hline Age (yrs) & $34.7 \pm 10.9$ & \\
\hline \multicolumn{3}{|l|}{ Sex } \\
\hline Male & 23 & 85.2 \\
\hline Female & 4 & 14.8 \\
\hline \multicolumn{3}{|l|}{ Mechanism of injury } \\
\hline Motor vehicle crash & 4 & 14.8 \\
\hline Motorcycle crash & 9 & 33.3 \\
\hline Auto/pedestrian accident & 6 & 22.2 \\
\hline Assault & 2 & 7.4 \\
\hline Fall from moving vehicle & 2 & 7.4 \\
\hline Fall from height/standing & 2 & 7.4 \\
\hline Sports injury & 1 & 3.7 \\
\hline Unknown & 1 & 3.7 \\
\hline Initial GCS score & $6.5 \pm 3.0$ & $3-14^{*}$ \\
\hline Initial motor GCS score & $3.5 \pm 1.7$ & $1-6^{*}$ \\
\hline Anisocoria & 7 & 25.9 \\
\hline AIS score & $29.1 \pm 8.8$ & $16-59^{*}$ \\
\hline \multicolumn{3}{|l|}{ Initial Marshall CT } \\
\hline D2 & 2 & 7.4 \\
\hline D3 & 3 & 11.1 \\
\hline M1 & 21 & 77.8 \\
\hline M2 & 1 & 3.7 \\
\hline \multicolumn{3}{|l|}{ Midline shift (mm) } \\
\hline No shift & 6 & 22.2 \\
\hline$<5$ & 6 & 22.2 \\
\hline $5-15$ & 13 & 48.1 \\
\hline$>15$ & 2 & 7.4 \\
\hline
\end{tabular}

AIS = Abbreviated Injury Scale.

Values represent the number of patients unless indicated otherwise. Means are presented \pm SDs.

* Value is not expressed as a percentage, but as a range.

for 1 patient at discharge. At 6 months follow-up, 7 patients were dead, 2 patients were in a persistent vegetative state, 8 patients had severe disability, 5 patients had moderate disability, and 1 patient had good recovery. Four patients were lost to follow-up at 6 months. Patients who were dead

TABLE 2. Number of patients for each global and regional CBF category after decompressive craniectomy for TBI

\begin{tabular}{lcccc}
\hline & \multicolumn{4}{c}{ CBF Category (ml/100 g/min) } \\
\cline { 2 - 5 } \multicolumn{1}{c}{ Location } & $\begin{array}{c}\text { Core } \\
(0-8)\end{array}$ & $\begin{array}{c}\text { Penumbra } \\
(9-30)\end{array}$ & $\begin{array}{c}\text { Normal } \\
(31-70)\end{array}$ & $\begin{array}{c}\text { Hyperemia } \\
(>70)\end{array}$ \\
\hline Global & 1 & 4 & 17 & 5 \\
\hline Under craniectomy defect & 1 & 7 & 16 & 3 \\
\hline Ipsilat cerebral hemisphere & 1 & 7 & 15 & 4 \\
\hline $\begin{array}{l}\text { Contralat cerebral hemi- } \\
\text { sphere }\end{array}$ & 0 & 4 & 18 & 5 \\
\hline
\end{tabular}



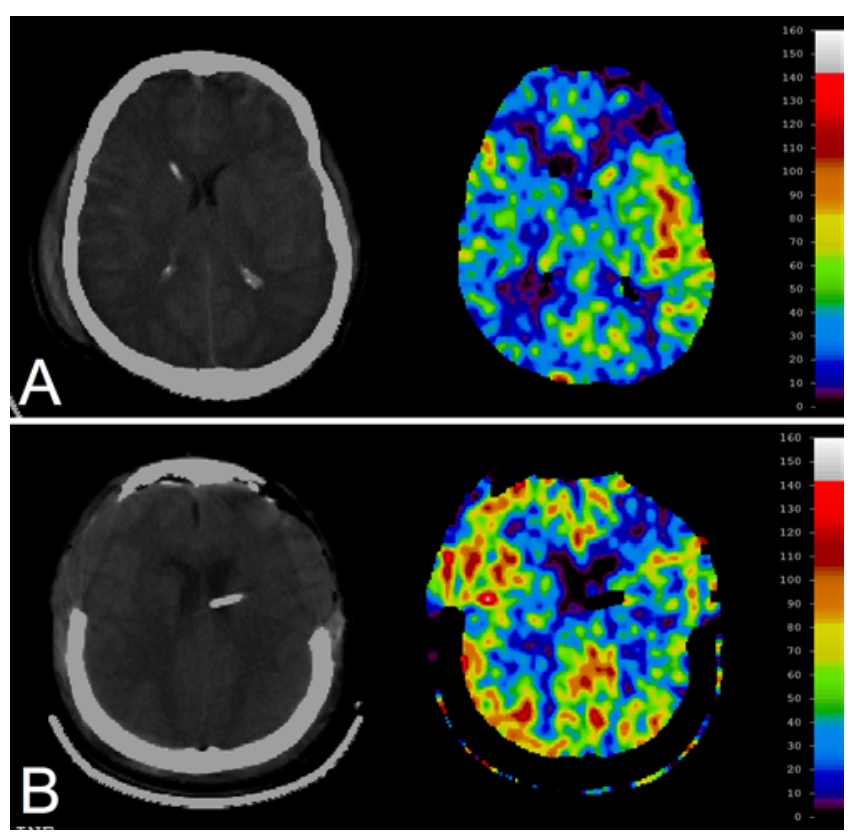

FIG. 3. Preoperative noncontrast head CT and XeCT CBF images (A) compared with postoperative images $(\mathbf{B})$ after bifrontal decompressive craniectomy showing improved cortical blood flow, particularly in the right hemisphere and frontal lobes. Figure is available in color online only.

at discharge had significantly lower postcraniectomy $\mathrm{CBF}$ under the craniectomy $(30.1 \pm 22.9$ vs $50.6 \pm 19.6 \mathrm{ml} / 100$ $\mathrm{g} / \mathrm{min} ; \mathrm{p}=0.039$ ). These patients also had lower global $\mathrm{CBF}(36.7 \pm 23.4$ vs $53.7 \pm 19.7 \mathrm{ml} / 100 \mathrm{~g} / \mathrm{min} ; \mathrm{p}=0.09)$, as well as lower CBF for the ipsilateral ( $33.3 \pm 27.2$ vs 51.8 $\pm 19.7 \mathrm{ml} / 100 \mathrm{~g} / \mathrm{min} ; \mathrm{p}=0.07)$ and contralateral $(36.7 \pm$ 19.2 vs $55.2 \pm 21.9 \mathrm{ml} / 100 \mathrm{~g} / \mathrm{min} ; \mathrm{p}=0.08$ ) hemispheres, but these differences were not statistically significant (Fig. 4). There was no significant difference in the mean arterial pressure between the groups $(85 \pm 4.6$ vs $91.2 \pm 9.2$ $\mathrm{mm} \mathrm{Hg} ; \mathrm{p}=0.13)$. Patients who died also had significantly lower CPP $(52 \pm 17.4$ vs $75.3 \pm 10.9 \mathrm{~mm} \mathrm{Hg} ; \mathrm{p}=0.001)$. Postoperative ICP was higher $(33 \pm 16.8$ vs $16.1 \pm 6.4 \mathrm{~mm}$ $\mathrm{Hg} ; \mathrm{p}=0.06)$ and $\mathrm{PbtO}_{2}$ was lower $(6 \pm 5.8$ vs $24.5 \pm 17.3$ $\mathrm{mm} \mathrm{Hg} ; \mathrm{p}=0.06$ ) in the mortality group, although these differences were not significantly different (Fig. 5).

$\mathrm{CBF}$ values were compared for patients with favorable GOS scores (good recovery and moderate disability) and unfavorable GOS scores (death, persistent vegetative state, and severe disability) at 6 months. There were no significant differences in global CBF $(50.2 \pm 30.7$ vs $46.9 \pm 20.1$ $\mathrm{ml} / 100 \mathrm{~g} / \mathrm{min} ; \mathrm{p}=0.76), \mathrm{CBF}$ under craniectomy defect $(53.6 \pm 29.9$ vs $41.6 \pm 19.9 \mathrm{ml} / 100 \mathrm{~g} / \mathrm{min} ; \mathrm{p}=0.28)$, ipsilateral hemispheric CBF $(51.9 \pm 29.8$ vs $44.9 \pm 21.9 \mathrm{ml} / 100$ $\mathrm{g} / \mathrm{min} ; \mathrm{p}=0.55)$, and contralateral hemispheric CBF (49.3 \pm 29.8 vs $49.0 \pm 21.7 \mathrm{ml} / 100 \mathrm{~g} / \mathrm{min} ; \mathrm{p}=0.98$ ).

\section{Discussion}

This study describes patterns of global and regional CBF visualized on XeCT CBF studies after decompressive craniectomy for TBI. In the presence of global hypoperfusion, regional cerebral hypoperfusion after decompressive craniectomy was significantly associated with early mortality after TBI. These findings were corroborated by impaired cerebral hemodynamics.

Few studies have described quantitative CBF patterns in patients who have undergone decompressive craniecto-

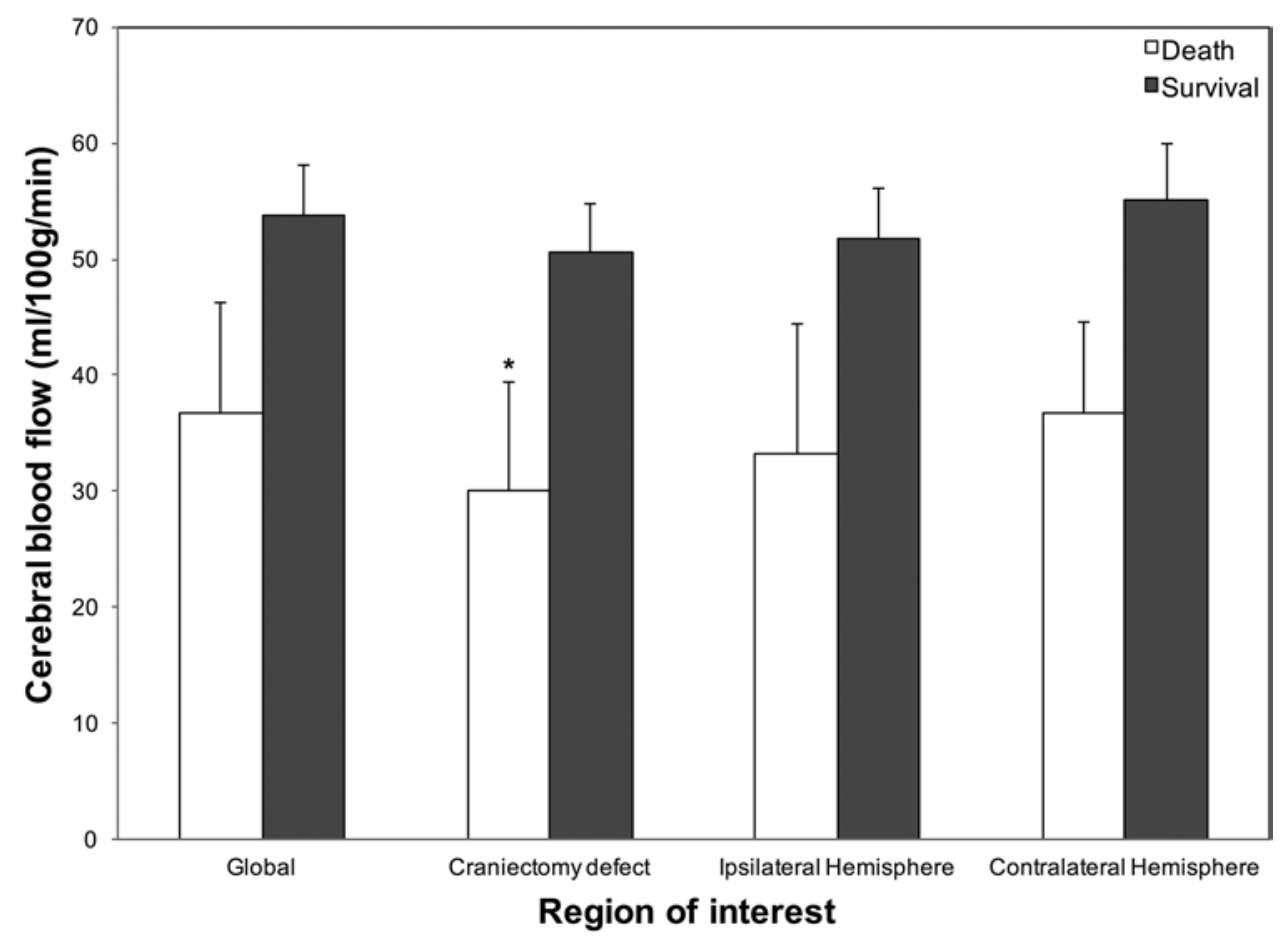

FIG. 4. Bar graph comparing global and regional CBF in patients who survived and in patients who died after decompressive craniectomy. ${ }^{*} p<0.05$. Error bars represent the standard error of the mean. 


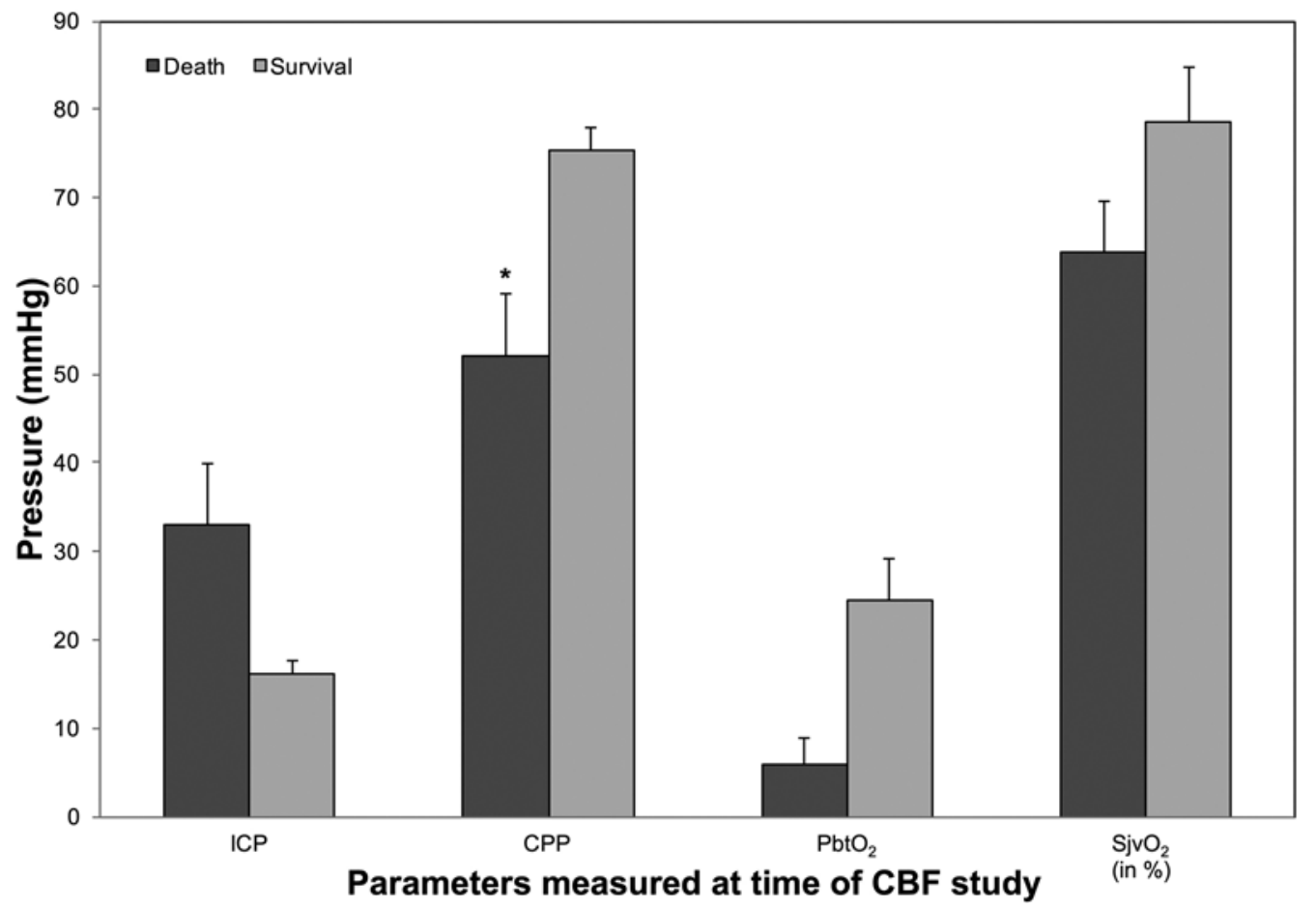

FIG. 5. Bar graph showing mean ICP, CPP, $\mathrm{PbtO}_{2}$, and $\mathrm{SjvO}_{2}$ at the time of $\mathrm{CBF}$ study for patients who survived and for those who died after decompressive craniectomy. ${ }^{*} p<0.05$. Error bars represent the standard error of the mean.

my for TBI. ${ }^{12}$ We used XeCT, which is a well-established modality to quantify global and regional $\mathrm{CBF}$ and has been used to predict clinical outcomes in TBI. ${ }^{6,9,11}$ The majority of patients $(81.5 \%)$ had normal and hyperemic global CBF values after decompressive craniectomy. Similarly, normal and hyperemic CBF values were observed under the craniectomy and on the ipsilateral cerebral hemisphere (in $70.4 \%$ of patients). XeCT was able to demonstrate regions of persistent hypoperfusion under the craniectomy defect, which probably represented areas of contusion and devitalized brain. Yamakami and Yamaura ${ }^{16}$ used SPECT imaging in 5 patients after decompressive craniectomy and showed transient focal hyperperfusion in the decompressed brain that lasted at least 1 week after decompressive craniectomy. In a pilot study, Heppner et al. ${ }^{8}$ used contrast-enhanced ultrasound to study microvascular cerebral perfusion after decompressive craniectomy in 6 patients; they showed increased CBF and cerebral blood volume up to 48 hours after surgery. Contrast-enhanced ultrasound, however, is restricted to measuring regional $\mathrm{CBF}$ and has not been validated with standard techniques to measure CBF. Other studies using transcranial Doppler to measure macrovascular flow after decompressive craniectomy have shown increased flow velocities in both hemispheres after surgery. ${ }^{3,5}$

Decompressive craniectomy for patients with TBI has been shown to produce favorable effects on cerebral hemodynamics, particularly a decrease in ICP and an increase in CPP. ${ }^{2}$ We found that CPP was significantly increased after surgery compared with before decompressive surgery. Improvements in brain oxygen tension have also been noted after decompressive craniectomy, indicating improved oxygen delivery to brain tissue. ${ }^{10,15}$ A normal
ICP with a low $\mathrm{PbtO}_{2}$ after decompressive craniectomy, however, is associated with a poor outcome.

In the present study, the majority of patients who died had a mismatch between ICP and $\mathrm{PbtO}_{2}$, as well as hypoperfusion on XeCT CBF. Two patients who died after decompressive craniectomy had ICP values $\leq 22 \mathrm{~mm} \mathrm{Hg}$, but $\mathrm{PbtO}_{2}<5 \mathrm{~mm} \mathrm{Hg}$ after surgery. Two additional patients who died had mildly elevated ICP $(24 \mathrm{~mm} \mathrm{Hg})$ and low $\mathrm{PbtO}_{2}(<15 \mathrm{~mm} \mathrm{Hg})$ after decompressive craniectomy. Optimizing the timing of decompressive craniectomy may restore $\mathrm{CBF}$ and $\mathrm{PbtO}_{2}$ in addition to reducing ICP and increasing CPP. Continued multimodal monitoring after decompressive craniectomy for TBI can detect persistent metabolic dysfunction and help guide further management and prognosis.

There are limited data on CBF patterns before and after decompressive craniectomy for TBI. Soustiel et al. ${ }^{14}$ used ultrasound to measure CBF before and after decompressive craniectomy in 7 patients and found a significant increase of approximately $4 \mathrm{ml} / 100 \mathrm{~g} / \mathrm{min}$. Using transcranial Doppler, Daboussi et al. ${ }^{5}$ showed an immediate, symmetric increase in CBF velocities in patients before and after decompressive craniectomy. In the present study, among the 10 patients with pre- and postcraniectomy CBF studies, CBF decreased in 2 patients, and low CBF before surgery persisted after decompressive craniectomy in 1 patient. These data point to a subset of patients who showed no improvement or worsened CBF after decompressive craniectomy. Further study is needed to determine whether precraniectomy CBF studies can help optimize the timing of decompressive craniectomy.

This study is limited by the small sample size and its retrospective design. These preliminary results show an 
association between low $\mathrm{CBF}$ and mortality and can help investigate mismatches between ICP and $\mathrm{PbtO}_{2}$ data after decompressive craniectomy. CBF studies may help to explain poor outcomes in future clinical trials for decompressive craniectomy in TBI. Presurgical CBF studies may have value in the selection and timing of secondary decompressive craniectomy in patients with diffuse injury and intractable intracranial hypertension.

Although XeCT CBF can produce high-resolution images of global and regional CBF in the brain, it has technical limitations; these include a relatively low signal-tonoise ratio, large slice thickness, and signal averaging, as well as the potential for xenon to variably activate CBF. ${ }^{17}$ Because xenon is not used clinically, other CBF measurement techniques (e.g., thermal diffusion microprobes, SPECT, PET, or CT perfusion ${ }^{1}$ ) can be used to further build on the results of this study. A larger sample size would have enabled us to perform a subgroup analysis for different types of decompressive craniectomy in addition to primary and secondary decompressive craniectomy. Overall, we used multimodal monitoring and XeCT CBF to describe cerebral hemodynamics after decompressive craniectomy and identified factors associated with early mortality.

\section{Conclusions}

The majority of patients (81.5\%) had normal and hyperemic global CBF after decompressive craniectomy. Persistent cerebral hypoperfusion after decompressive craniectomy was associated with early mortality after severe TBI. Further study is needed to determine the value of incorporating $\mathrm{CBF}$ studies into clinical decision making for severe TBI.

\section{References}

1. Akbik OS, Carlson AP, Krasberg M, Yonas H: The utility of cerebral blood flow assessment in TBI. Curr Neurol Neurosci Rep 16:72, 2016

2. Bor-Seng-Shu E, Figueiredo EG, Amorim RLO, Teixeira MJ, Valbuza JS, de Oliveira MM, et al: Decompressive craniectomy: a meta-analysis of influences on intracranial pressure and cerebral perfusion pressure in the treatment of traumatic brain injury. J Neurosurg 117:589-596, 2012

3. Bor-Seng-Shu E, Hirsch R, Teixeira MJ, De Andrade AF, Marino R Jr: Cerebral hemodynamic changes gauged by transcranial Doppler ultrasonography in patients with posttraumatic brain swelling treated by surgical decompression. J Neurosurg 104:93-100, 2006

4. Cooper DJ, Rosenfeld JV, Murray L, Arabi YM, Davies AR, D'Urso P, et al: Decompressive craniectomy in diffuse traumatic brain injury. N Engl J Med 364:1493-1502, 2011

5. Daboussi A, Minville V, Leclerc-Foucras S, Geeraerts T, Esquerré JP, Payoux P, et al: Cerebral hemodynamic changes in severe head injury patients undergoing decompressive craniectomy. J Neurosurg Anesthesiol 21:339-345, 2009

6. Fridley J, Robertson C, Gopinath S: Quantitative lobar cerebral blood flow for outcome prediction after traumatic brain injury. J Neurotrauma 32:75-82, 2015

7. Gennarelli TA, Wodzin E: AIS 2005: a contemporary injury scale. Injury 37:1083-1091, 2006

8. Heppner P, Ellegala DB, Durieux M, Jane JA Sr, Lindner JR:
Contrast ultrasonographic assessment of cerebral perfusion in patients undergoing decompressive craniectomy for traumatic brain injury. J Neurosurg 104:738-745, 2006

9. Hlatky R, Contant CF, Diaz-Marchan P, Valadka AB, Robertson CS: Significance of a reduced cerebral blood flow during the first 12 hours after traumatic brain injury. Neurocrit Care 1:69-83, 2004

10. Ho CL, Wang CM, Lee KK, Ng I, Ang BT: Cerebral oxygenation, vascular reactivity, and neurochemistry following decompressive craniectomy for severe traumatic brain injury. J Neurosurg 108:943-949, 2008

11. Kaloostian P, Robertson C, Gopinath SP, Stippler M, King CC, Qualls C, et al: Outcome prediction within twelve hours after severe traumatic brain injury by quantitative cerebral blood flow. J Neurotrauma 29:727-734, 2012

12. Lazaridis C, Czosnyka M: Cerebral blood flow, brain tissue oxygen, and metabolic effects of decompressive craniectomy. Neurocrit Care 16:478-484, 2012

13. Maas AI, Hukkelhoven CW, Marshall LF, Steyerberg EW: Prediction of outcome in traumatic brain injury with computed tomographic characteristics: a comparison between the computed tomographic classification and combinations of computed tomographic predictors. Neurosurgery 57:11731182,2005

14. Soustiel JF, Sviri GE, Mahamid E, Shik V, Abeshaus S, Zaaroor M: Cerebral blood flow and metabolism following decompressive craniectomy for control of increased intracranial pressure. Neurosurgery 67:65-72, 2010

15. Stiefel MF, Heuer GG, Smith MJ, Bloom S, Maloney-Wilensky E, Gracias VH, et al: Cerebral oxygenation following decompressive hemicraniectomy for the treatment of refractory intracranial hypertension. J Neurosurg 101:241-247, 2004

16. Yamakami I, Yamaura A: Effects of decompressive craniectomy on regional cerebral blood flow in severe head trauma patients. Neurol Med Chir (Tokyo) 33:616-620, 1993

17. Yonas H, Darby JM, Marks EC, Durham SR, Maxwell C: CBF measured by Xe-CT: approach to analysis and normal values. J Cereb Blood Flow Metab 11:716-725, 1991

\section{Disclosures}

The authors report no conflict of interest concerning the materials or methods used in this study or the findings specified in this paper.

\section{Author Contributions}

Conception and design: Vedantam, Robertson. Acquisition of data: Vedantam, Robertson. Analysis and interpretation of data: Vedantam, Robertson. Drafting the article: Vedantam. Critically revising the article: all authors. Reviewed submitted version of manuscript: all authors. Approved the final version of the manuscript on behalf of all authors: Gopinath. Statistical analysis: Vedantam. Administrative/technical/material support: Gopinath, Robertson. Study supervision: Gopinath, Robertson.

\section{Supplemental Information \\ Previous Presentations}

Portions of this work were submitted in abstract form to the AANS Annual Scientific Meeting, Los Angeles, CA, April 22-26, 2017.

\section{Correspondence}

Shankar P. Gopinath, Department of Neurosurgery, Baylor College of Medicine, 7200 Cambridge St., Ste. 9A, MS: BCM650, Houston, TX 77030. email: shankarg@bcm.edu. 